\title{
Simple Rheological Analysis Method of Spinnable-Polymer Flow Properties Using MFI Tester
}

\author{
Basel Younes \\ Textiles Department, Faculty of Mechanical and Electrical Engineering, Damascus University, P.O. Box 86, Damascus, Syria \\ Correspondence should be addressed to Basel Younes; younesbasel@yahoo.co.uk
}

Received 19 May 2015; Accepted 16 June 2015

Academic Editor: Kanai Sahoo

Copyright (C) 2015 Basel Younes. This is an open access article distributed under the Creative Commons Attribution License, which permits unrestricted use, distribution, and reproduction in any medium, provided the original work is properly cited.

\begin{abstract}
Rheological characterization of polymers explains the flow behaviour and viscoelastic properties and tests fibre-forming ability. The current method investigates the viscoelastic properties and morphology of polymers and finds the rheological data and the right polymer viscosity, which is determining the best processing temperature. The right processing temperature saves the power, the material, and the time needed for production. After calculating polymers viscosity by using MFI tester, the method investigates rheological properties and surface shape at different temperatures and loads. The method could apply to other polymers to find the viscosity-temperature change and to set the best processing temperature.
\end{abstract}

\section{Introduction}

Since the polymer melts differ in size, weight, and degree of freedom, the microstructure of the materials has to be taken into account in order to describe typical features of non-Newtonian fluid behaviour. Melt flow index (MFI) is one of the most important properties for the quality control of polymers. The higher the MFI, the lower the resin velocity and the molecular weight [1]. By using this method, there is no need for the viscometer tester; the MFI tester results will help in calculating the polymer viscosity.

\section{Recommended Equipment}

2.1. Sample Preparation. Eastar Bio, based on Butandiol, adipic acid, and terephthalic acid, used to test this method, made by Eastman and supplied by Rodenburg Company, Netherlands. The polymer shape is spherical granule resin in diameter $3-5 \mathrm{~mm}$, with density of $1.22 \mathrm{~g} / \mathrm{cm}^{3}$. The used material is referred to [2]: 1,4-benzenedicarboxylic acid, polymer with 1,4-butanediol, and hexanedioic acid known as aliphatic-aromatic copolyester (AAC). Two grades were used and coded as AACl and AAC2. The moisture effect should be taken into account in this method (Figure 1). The moisture effect was solved by drying the used polymer at $60^{\circ} \mathrm{C}$ for 6 hours and keeps it away from the moisture resource before use.

2.2. Thermal Analysis Using Differential Scanning Calorimetry (DSC). Differential scanning calorimetry (DSC) is a thermal analysis used to determine physical changes, chemical changes, or the degree of the crystallinity of the polymers through measuring the enthalpy and comparing it with the enthalpy of a crystalline sample of the same material [3]. METTLER-TA Instrument and METTLER-TOLEDOTA89E System software were used to determine the thermal curves of the used polymer.

2.3. Melt Flow Tester. MFI tester, A Ray-Ran 5 Series Advanced Melt Flow System, was used to measure the melt flow index (MFI) [4]. MFI ( $/ 10 \mathrm{~min}$ ) measures the mass in grams of a thermoplastic material through a standard size capillary at known temperature for 10 minutes [5].

2.4. Texas Instrument or Microsoft Office Excel. A Texas Instrument (Figure 2) with TI-83 Plus Software Development Kit (SDK) was used in the method to write calculator programs (as forecasting applications) using a variety of the calculator's internal functions. The Texas Instrument offers the ability to load and debug programs, applications, and 


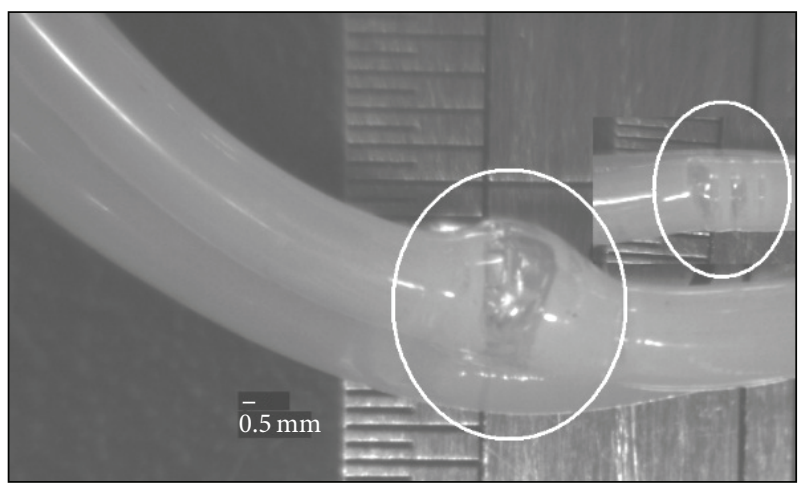

Figure 1: The moisture effect on the extrudate.

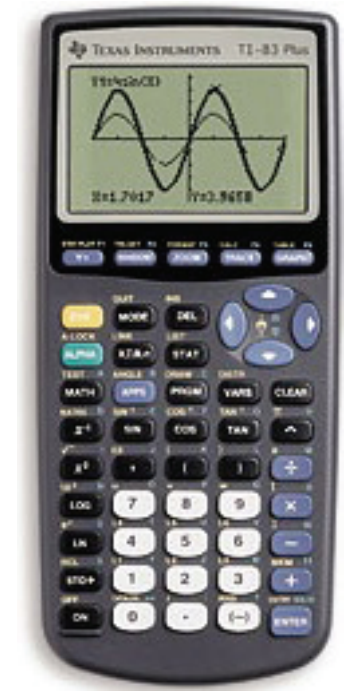

Figure 2: Texas Instrument TI-83 Plus.

breakpoint. The method could use Microsoft Office Excel Software instead of Texas Instrument by using the equations generated in this method.

\section{Background of Method}

In Newtonian fluids, it is possible to calculate the flow properties through some equations as we will describe below. The mean diameter of the piston and the cylinder is $D=$ $9.5504 \mathrm{~mm}$ and capillary diameter and capillary length are $d=2.0955 \mathrm{~mm}$ and $L=8.000 \mathrm{~mm}$. The MFI tester and a schematic diagram of the pressure distribution in the reservoir and the capillary are shown in Figure 3. As the piston is moved down by the weight, the molten polymer is forced through the capillary.

As the piston diameter $(D)$ is bigger than the capillary diameter $(d)$, the wall shear stress $\tau$ in the capillary can be related to the force on the piston, and the entrance effects are ignored, and the wall shear stress can be calculated then using the following equation:

$$
\tau=\frac{\Delta P d}{4 L}
$$

where $\Delta P$ is the pressure dropped along the capillary and $L$ is capillary length [6]. $\Delta P$ can be calculated by the following equation:

$$
\begin{aligned}
\Delta P & =P(l=L)-P(l=0)=\left[\frac{4 F}{\pi \cdot D^{2}}+P_{0}\right]-\left[P_{0}\right] \\
& =\frac{4 F}{\pi \cdot D^{2}},
\end{aligned}
$$

where $F$ is the weight on the plunger in grams.

The shear stress $\tau$ at the capillary wall is determined by the following equation:

$$
\tau=\frac{F \cdot d}{\pi \cdot L \cdot D^{2}}=8.97 F(\mathrm{pa}) .
$$

The apparent shear rate $\gamma$ at the capillary wall can be determined from the flow rate $v$ through the capillary and it can be expressed as follows $[6,7]$ :

$$
\gamma_{\mathrm{APP}}=\frac{32 \cdot v}{\pi \cdot d^{3}} .
$$

The flow rate or volumetric throughout $\left(v, \mathrm{~cm}^{3} / \mathrm{s}\right)$ is determined by the area $\left(\mathrm{cm}^{2}\right)$ and the piston velocity $(v, \mathrm{~cm} / \mathrm{s})$ or by the MFI value and the melt density at the current temperature $\left(\rho_{t}\right)[8]$ :

$$
\begin{aligned}
v & =\frac{\pi \cdot v \cdot D^{2}}{4}=\frac{\pi \cdot l \cdot D^{2}}{4 \cdot t}=\frac{V}{t}=\frac{V \cdot \rho_{t}}{t \cdot \rho_{t}}=\frac{m}{\rho_{t}} \\
& =\frac{\mathrm{MFI}}{600 \times \rho_{t}}(\mathrm{~g} / \mathrm{s}),
\end{aligned}
$$

where $v$ (velocity) $=l$ (distance) $/ t$ (time) and $V$ is the volume.

The apparent shear rate $\gamma_{\mathrm{APP}}$ at the capillary wall can now be expressed as a function of the MFI [8]:

$$
\begin{aligned}
\gamma_{\text {app }} & =\frac{32 \cdot \mathrm{MFI}}{600 \times \pi \times d^{3} \times \rho_{t}}=\frac{1.845 \times \text { MFI }}{\rho_{t}} \\
& =1.845 \mathrm{v}\left(\mathrm{s}^{-1}\right) .
\end{aligned}
$$

The apparent viscosity $\eta_{\text {app }}$ can be determined by dividing the shear stress by the apparent shear rate [8] as shown in the following equation:

$$
\begin{aligned}
\eta_{\text {app }} & =\frac{\tau}{\gamma_{\text {app }}}=\frac{600 \times \pi \times d^{3} \times \rho_{t} \times F \times d}{32 \cdot \mathrm{MFI} \times L \times \pi \times D^{2}} \\
& =\frac{58.904862 \times F \times d^{4}}{\pi \times L \times D^{2} \times v}=\frac{4.86 F}{v}(\mathrm{pa} \cdot \mathrm{s}) .
\end{aligned}
$$

Because software engineering programs do not reflect the need by the industry for practising software, the Texas Instrument could develop suitable applications, which could be connected to melt spinning specifications and requirements for embedded real-time systems. Otherwise, we can use (1) to (7) in Microsoft Office Excel Software and calculate the results depending on the measurement obtained from the MFI tester that will describe the method steps and results' calculation. 


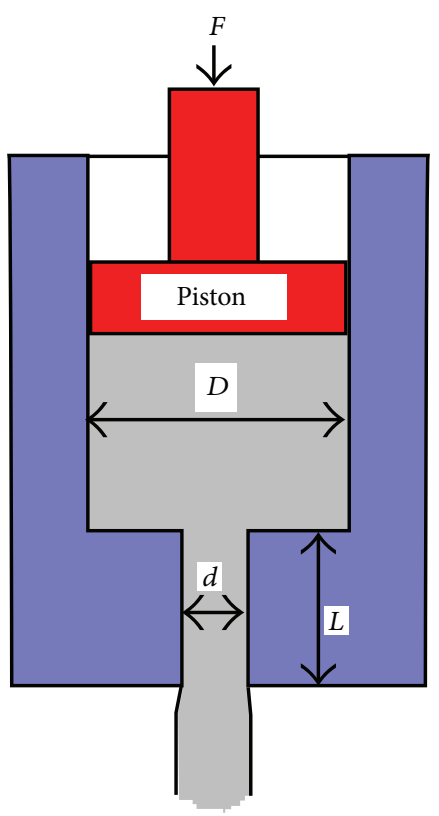

Extruded strand

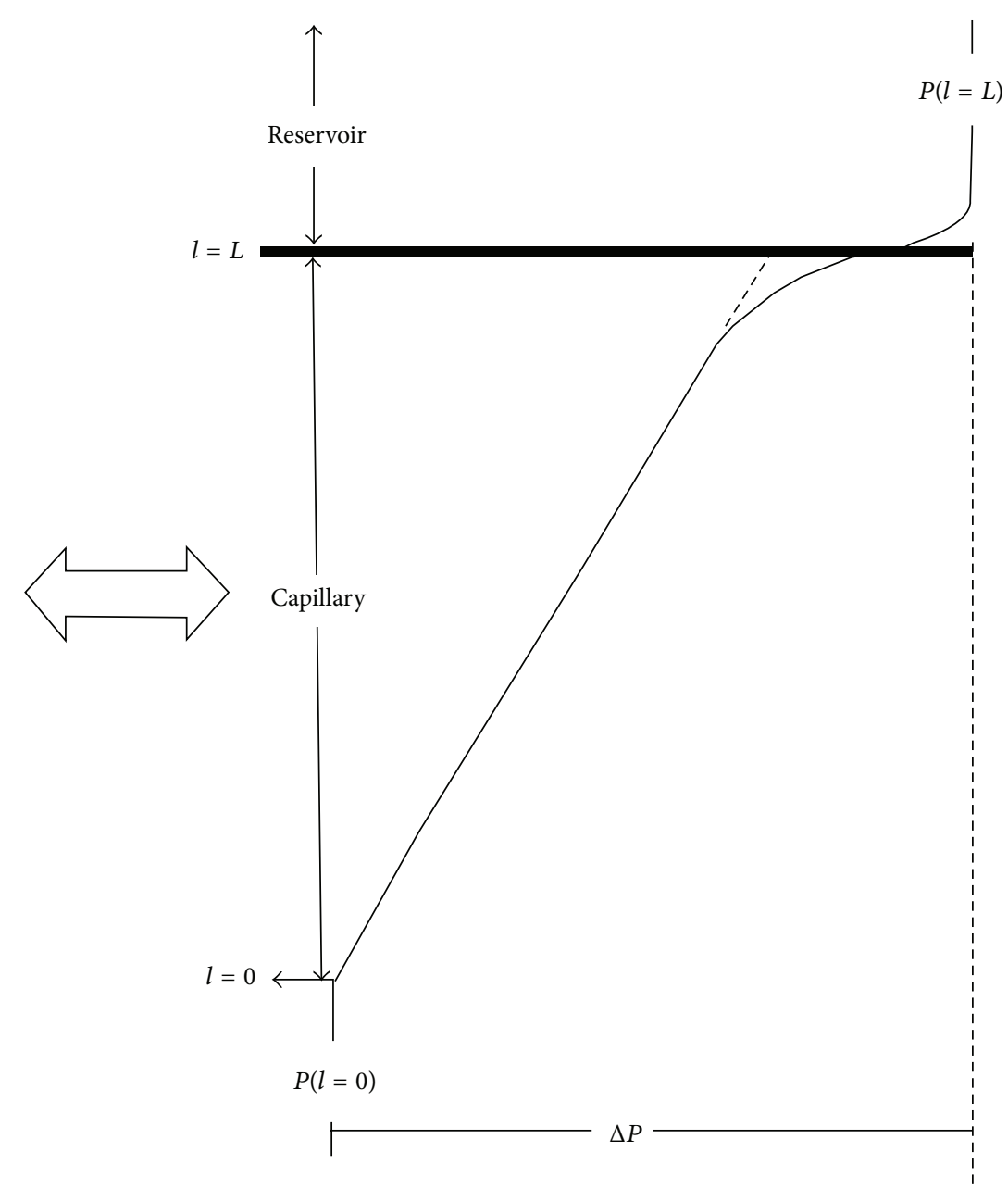

FIgURE 3: The MFI tester with schematic diagram of the pressure distribution in the capillary.

\section{Method Steps and Results' Calculations}

To study the effects of polymer grade on the production process and the properties of as-spun aliphatic-aromatic copolyester fibres, two grades of AACs were coded as MFI1 (AAC1) and MFI2 (AAC2) depending on their melt flow indices. Note that the measured melt flow index (MFI) does not fully present the properties of the polymer.

In the rheological studies, different pressures were applied to the melt via a piston using different loads of total mass $(F)$ of $2.16,3.16$, and $5.00 \mathrm{~kg}$ at different temperatures of 120 , 125,130 , and $135^{\circ} \mathrm{C}$. According to DSC results, the polymer does not melt completely below $120^{\circ} \mathrm{C}$, and the starting temperature was taken as $120^{\circ} \mathrm{C}$ as it has been observed.

The piston diameter $(D=9.5504 \mathrm{~mm})$ was bigger than the capillary diameter $(d=2.0955 \pm 0.0051)$ and the pressure dropped along the capillary $(\Delta P) . L$ is the capillary length $(L=8.000 \pm 0.0250 \mathrm{~mm}, L / d=3.8177)$ and $P(I=0)$ is the atmospheric pressure. When the piston was moved down by the weight, the molten polymer was forced through the die; below is the steps of this method.

(1) According to the differential scanning calorimetry (DSC) results in Figure 4, an optimum temperature

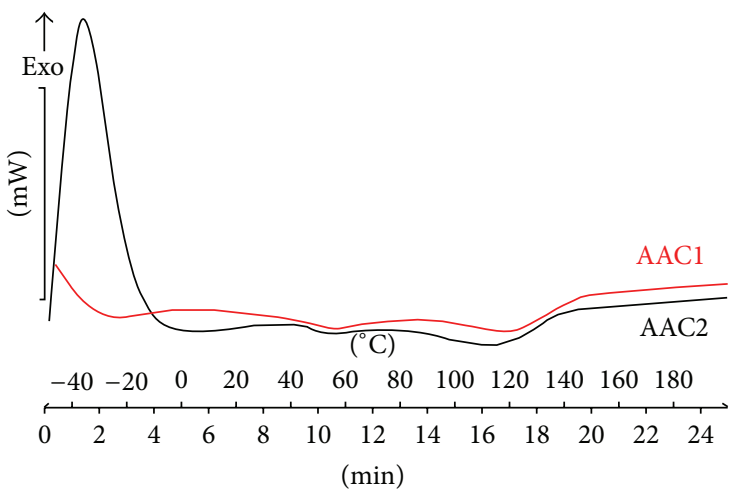

FIgURE 4: Thermal diagram of AACs.

window for method was designed taking all factors into account because the polymer does not melt over a narrow range and does not melt completely below $120^{\circ} \mathrm{C}$, the starting temperature of test in the method. The thermal diagrams of the two grades show that a broad temperature range of melting (about 100$135^{\circ} \mathrm{C}$ ) was observed for the polymer samples. 


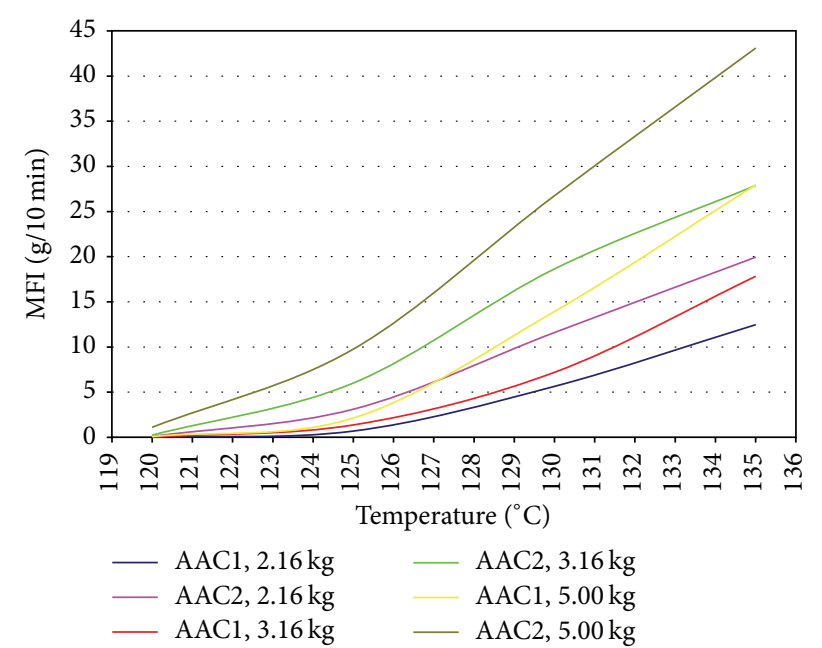

FIGURE 5: The relationship between MFI, the pressure (weight), and temperature.

(2) MFI values according to ASTM D-1238 for the tested polymer are drawn in Figure 5; the MFI was measured at different loads $(2.16,3.16$, and $5 \mathrm{Kg})$ and temperatures $\left(120-135^{\circ} \mathrm{C}\right)$. The relationship between flow (MFI), the pressure, and temperature is not linear, and that is related to the nonlinear change in viscosity with change in pressure or temperature. The relationship between (MFI), pressure, and temperature is not linear and is related to the nonlinear change in viscosity with change in pressure and/or temperature. On the other hand, the productivity will be increased if the temperature or the pressure is increased and that will be limited depending on the polymer degradation and hence the properties of the product.

(3) As a function of temperature, the density is measured at $2.16 \mathrm{~kg}$ load and different temperature and Table 1 shows the change in specific gravity. Bearing in mind that the polymer is not exposed to a uniform shear rate and the measurement could be unreliable at higher shear rate as result of temperature effects and viscoelastic behaviour, the viscosity varies inversely with the temperature and pressure, and that is clear from the increasing of MFI with the increase of both temperature and pressure. If the entrance effect will be considerable, there are errors in the expression for the wall shear stress and the apparent viscosity.

(4) Depending on the MFI results and Table 1 and using (5), the volumetric throughout results are calculated and listed in Table 2.

(5) Depending on the results from Table 3 and using (6), the shear rate can be calculated as shown in Table 3 .

(6) As it is explained before, the shear stress depends on the load and it is calculated by using (3) and listed in Table 4.

(7) The viscosity of AAC is measured at various shear rates, temperatures, and loads; it is calculated by (7) and listed in Table 5. In non-Newtonian fluids, the actual value of the shear rate at the capillary depends on the fluid behavior as a power law fluid with power law index; the viscosity curves of viscosity and shear rate are converted to true viscosity curves using the Rabinowitsch correction [9].

The viscosity ratio affects the capillary instability of fluid jets and helps in determining melt spinning conditions. If the entrance effect is considerable, there are errors in the expression for the wall shear stress and the apparent viscosity; this drawback is negated by running the melt indexer with several different weights $[10,11]$.

\section{Rheological and Thermal Characterizations}

Viscosity varies inversely with the temperature and pressure, which is clear from the increase in MFI, with the increase of both temperature and pressure. Alternatively, the productivity (a measure of throughput per minute $\left(\mathrm{g} \cdot \mathrm{min}^{-1}\right)$ ) will be increased if the temperature or the pressure is increased and will be limited depending on the polymer degradation. The apparent viscosity dramatically decreases with the MFI increasing under loads 2.16, 3.16, and $5 \mathrm{~kg}$. Figure 6 shows different magnifications of MFI-apparent viscosity graph of $\mathrm{AACl}$ and $\mathrm{AAC2}$. A high MFI corresponds to a low polymer melt viscosity and a low MFI corresponds to a high polymer melt viscosity, which agrees with the lectures. At low MFI and high viscosity, the polymer will have high power consumption and die-head pressure in the extrusion [8].

Figures 7 and 8 show the extrudates' appearance at different temperatures, apparent shear rate, and viscosity. The analysis will give an explanation for the character of the rheological and thermal properties and surface shape at the different conditions in which recent analysis was performed. In terms of extrudate surface analysis for both grades, smooth extrudate can be observed above $130^{\circ} \mathrm{C}$ and "shark skin" extrudate can be observed between $125^{\circ} \mathrm{C}$ and $130^{\circ} \mathrm{C}$. A "shark skin" surface was formed by a series of ridges aligned perpendicular to the flow direction. It could be distinguished from an elastic turbulence, which belongs to the material nature and sometimes to the polymer-die metal adhesion [9]. The apparent extrudate swell depends on the die entry and the die exit and possible slip at the polymer-wall interface [12].

Stick-slip or oscillating melt extrudate appears at $125^{\circ} \mathrm{C}$, and gross melt fractured extrudate was found at $120^{\circ} \mathrm{C}$; it could be observed at the lower extrusion rate and depended on the temperature, as described previously. Melt instability can be caused by an exclusive increase in shear stress and stick-slip, or the shark skin effect will appear. Depending on theoretical formulas and MFI results analysis, the viscosity decreased and the material flowed easily at higher temperatures. At shear rates more than $5 \mathrm{~s}^{-1}$, the extrudate surface was practically and quite smooth up to $15 \mathrm{~s}^{-1}$, whereas smoother extrudates were obtained at shear rates of more than $15 \mathrm{~s}^{-1}$. Under processing, the viscoelastic nature of polymeric fluids of some materials has many complex effects on the flow stability [13] and the other properties, such as molecular 


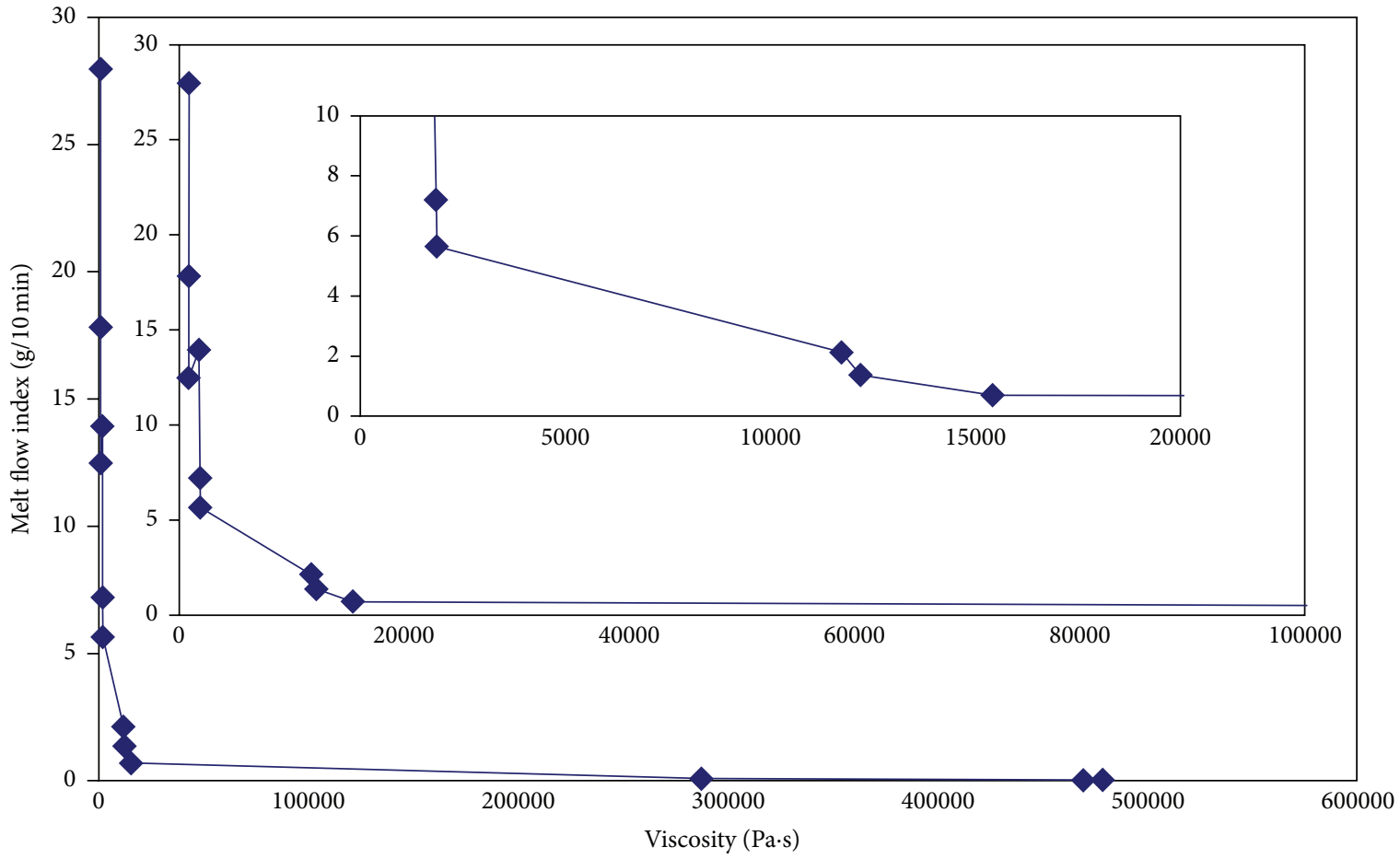

(a)

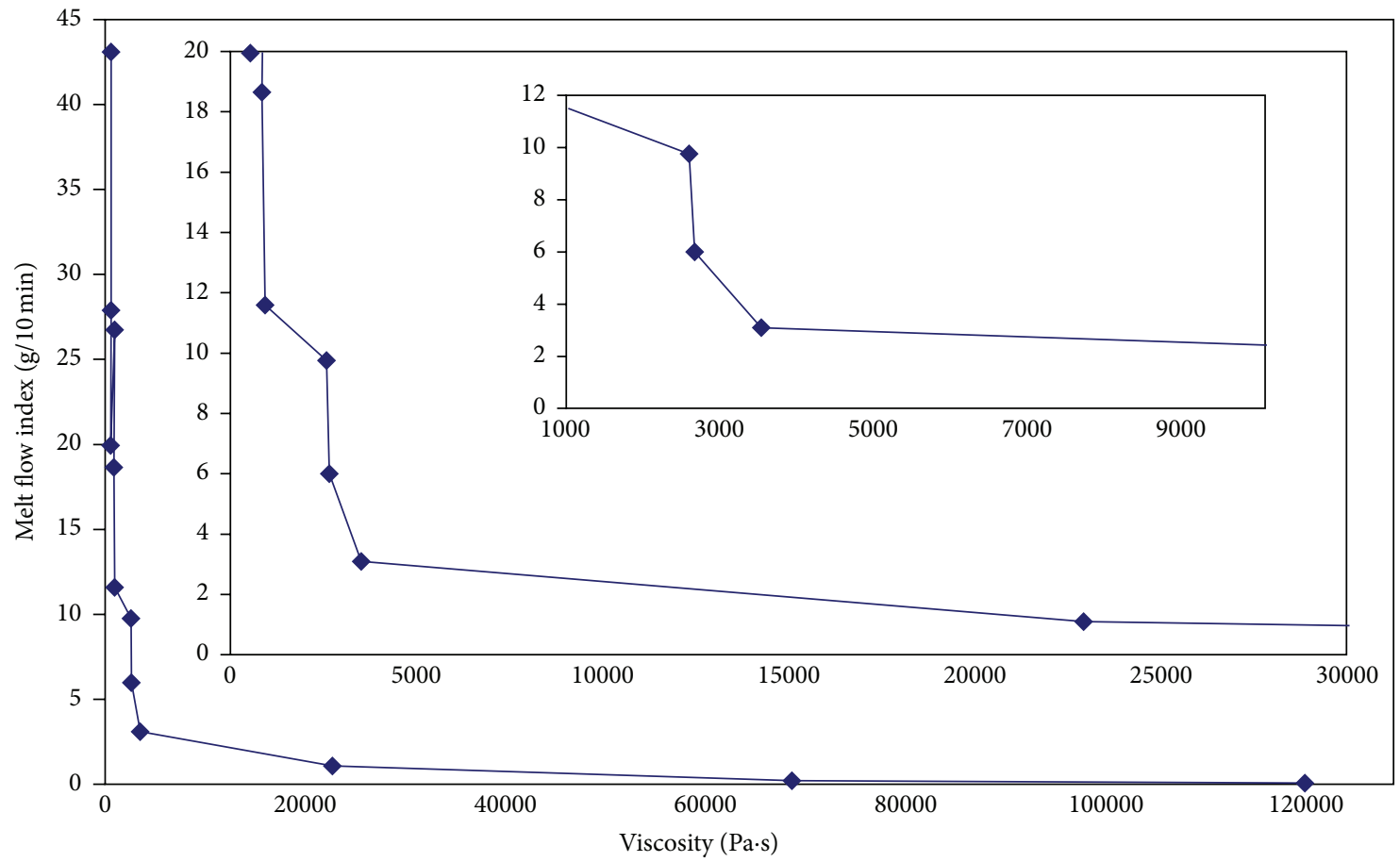

(b)

FIGURE 6: The magnification plots in Figure 6 show the high power consumption and the rheological aspects of AAC1 and AAC2 under different processing conditions. 
TABLE 1: The melt density at different temperature.

\begin{tabular}{lccccc}
\hline$T\left({ }^{\circ} \mathrm{C}\right)$ & \multicolumn{2}{c}{$M(\mathrm{~g})$} & $\begin{array}{l}V\left(\mathrm{~cm}^{3}\right) \\
(\text { constant })\end{array}$ & \multicolumn{2}{c}{ The melt density $\left(\rho_{t}, \mathrm{~g} / \mathrm{cm}^{3}\right)$} \\
AAC1 & AAC2 & & AAC1 & 1.028343 \\
135 & 2.14 & 2.210 & $\mathbf{2 . 1 4 9 0 8 8 3}$ & 1.00595771 & 1.032996 \\
130 & 2.16 & 2.220 & at a load of $\mathbf{2 . 1 6} \mathbf{~ k g}$ & 1.028343 & 1.037649 \\
125 & 2.21 & 2.230 & & 1.028343 & 1.037649 \\
120 & 2.21 & 2.230 & & \\
\hline
\end{tabular}

TABLE 2: The volumetric throughout $\left(v, \mathrm{~cm}^{3} / 10 \mathrm{~min}\right)$ at different loads and temperatures.

\begin{tabular}{|c|c|c|c|c|c|c|c|c|}
\hline \multirow{4}{*}{ Weight $(\mathrm{kg})$} & \multicolumn{8}{|c|}{ Temperature $\left({ }^{\circ} \mathrm{C}\right)$} \\
\hline & \multicolumn{2}{|c|}{120} & \multicolumn{2}{|c|}{125} & \multicolumn{2}{|c|}{130} & \multicolumn{2}{|c|}{135} \\
\hline & $\mathrm{AACl}$ & AAC2 & $\mathrm{AACl}$ & AAC2 & AAC1 & AAC2 & $\mathrm{AAC1}$ & AAC2 \\
\hline & \multicolumn{8}{|c|}{ The volumetric throughout $\left(v, \mathrm{~cm}^{3} / 10 \mathrm{~min}\right)$} \\
\hline 2.16 & 0.0223661 & 0.0867345 & 0.6807067 & 2.9875228 & 5.621460 & 11.229472 & 12.533002 & 19.400142 \\
\hline 3.16 & 0.0320905 & 0.2216549 & 1.3322403 & 5.7823021 & 7.163630 & 18.054281 & 17.905723 & 27.131025 \\
\hline 5.00 & 0.0846021 & 1.0600887 & 2.0712933 & 9.4058781 & 13.869584 & 25.895550 & 28.078745 & 41.912086 \\
\hline
\end{tabular}

TABLE 3: The shear rate $\left(\gamma_{\text {app }}, \mathrm{s}^{-1}\right)$ at different loads and temperatures.

\begin{tabular}{|c|c|c|c|c|c|c|c|c|}
\hline \multirow{4}{*}{ Weight (kg) } & \multicolumn{8}{|c|}{ Temperature $\left({ }^{\circ} \mathrm{C}\right)$} \\
\hline & \multicolumn{2}{|c|}{120} & \multicolumn{2}{|c|}{125} & \multicolumn{2}{|c|}{130} & \multicolumn{2}{|c|}{135} \\
\hline & $\mathrm{AAC1}$ & AAC2 & $\mathrm{AACl}$ & AAC2 & AAC1 & AAC2 & $\mathrm{AAC1}$ & AAC2 \\
\hline & \multicolumn{8}{|c|}{ The shear rate $\left(\gamma_{\mathrm{app}}, \mathrm{s}^{-1}\right)$} \\
\hline 2.16 & 0.04126541 & 0.160025153 & 1.25590392 & 5.511979566 & 10.37159342 & 20.71837584 & 23.12338881 & 35.79326199 \\
\hline 3.16 & 0.05920690 & 0.408953291 & 2.45798338 & 10.66834737 & 13.21689781 & 33.31014845 & 33.03605950 & 50.05674113 \\
\hline 5.00 & 0.15609092 & 1.955863652 & 3.82153620 & 17.35384509 & 25.58938270 & 47.77728975 & 51.80528455 & 77.32779867 \\
\hline
\end{tabular}

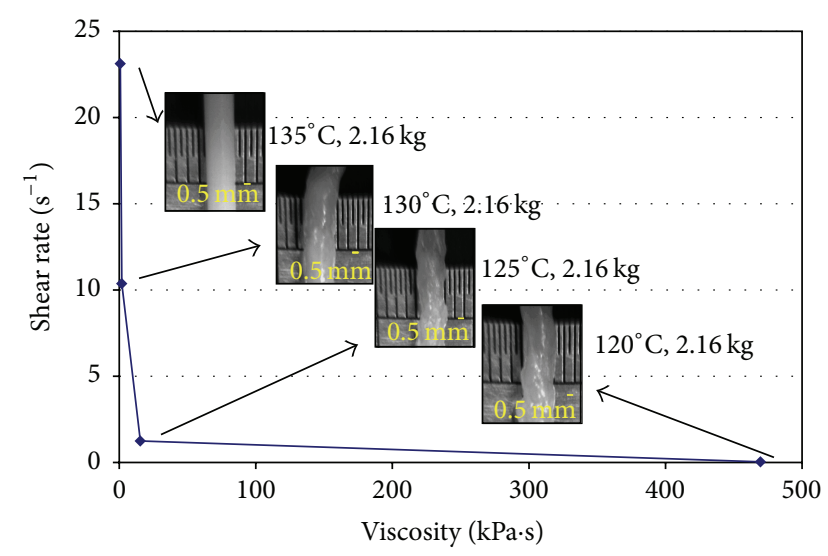

FIGURE 7: The surface shape at different temperature, viscosity, and shear rate at a load of $2.16 \mathrm{~kg}$ for LAAC1.

TABLE 4: The shear stress ( $\tau$, pa) at different loads and temperatures.

\begin{tabular}{|c|c|c|c|c|}
\hline \multirow{3}{*}{ Weight (kg) } & \multicolumn{4}{|c|}{ Temperature $\left({ }^{\circ} \mathrm{C}\right)$} \\
\hline & 120 & 125 & 130 & 135 \\
\hline & \multicolumn{4}{|c|}{ The shear stress $(\tau, \mathrm{pa})$} \\
\hline 2.16 & 19375.2 & 19375.2 & 19375.2 & 19375.2 \\
\hline 3.16 & 28345.2 & 28345.2 & 28345.2 & 28345.2 \\
\hline 5.00 & 44850.0 & 44850.0 & 44850.0 & 44850.0 \\
\hline
\end{tabular}

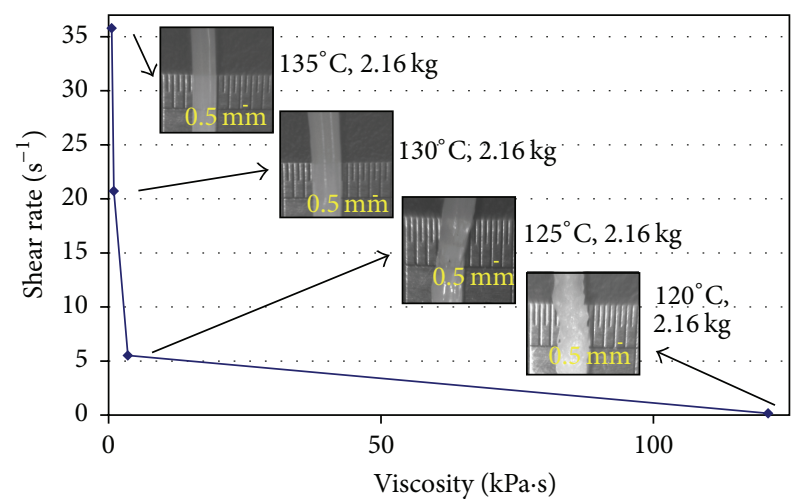

FIGURE 8: The surface shape at different temperature, viscosity, and shear rate at a load of $2.16 \mathrm{~kg}$ for LAAC2.

mobility and dyeability of the produced synthetic fibres [14, $15]$.

If the local power law index can be obtained, the viscosity curves of viscosity and shear rate (Figure 9) could be converted to true viscosity curves using the Rabinowitsch correction. Analysis shows that as the temperature increases, the shear decreases and the shear rate increases as a result of the viscosity decreases. Thus, the increase in shear rate results 
TABLE 5: The viscosity of AAC $\left(\eta_{\text {app }}\right.$, pa $\left.s\right)$ at different loads and temperatures.

\begin{tabular}{|c|c|c|c|c|c|c|c|c|}
\hline \multirow{4}{*}{ Weight (kg) } & \multicolumn{8}{|c|}{ Temperature $\left({ }^{\circ} \mathrm{C}\right)$} \\
\hline & \multicolumn{2}{|c|}{120} & \multicolumn{2}{|c|}{125} & \multicolumn{2}{|c|}{130} & \multicolumn{2}{|c|}{135} \\
\hline & $\mathrm{AAC1}$ & AAC2 & $\mathrm{AAC1}$ & AAC2 & $\mathrm{AACl}$ & AAC2 & $\mathrm{AAC1}$ & AAC2 \\
\hline & \multicolumn{8}{|c|}{ The viscosity $\left(\eta_{\text {app }}\right.$, pa.s $)$} \\
\hline 2.16 & 469526.4 & 121076.00 & 15427.29 & 3515.107 & 1868.103 & 935.1698 & 837.9049 & 541.3086 \\
\hline 3.16 & 478748.3 & 69311.58 & 11531.89 & 2656.944 & 2144.618 & 850.9479 & 858.0079 & 566.2614 \\
\hline 5.00 & 287332.5 & 22931.05 & 11736.12 & 2584.442 & 1752.68 & 938.7305 & 865.7418 & 579.9984 \\
\hline
\end{tabular}

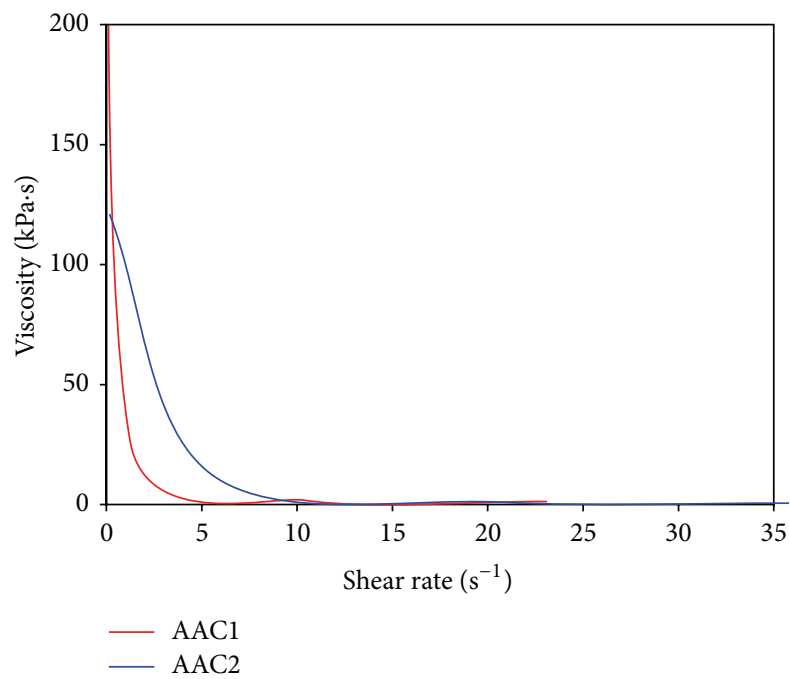

FIGURE 9: Viscosity-shear rate curve at a load of $2.16 \mathrm{~kg}$.

in a decrease in the viscosity for a particular temperature. At the same load and as MFI increases, the piston speed is increased. The shear rate increases as a result of the die-head pressure and the shear stress (load) increasing. The overall thermal behaviour of the grades used in this method allows the conclusion that the processing window is quite wide. Therefore, the used polymer can be safely extruded from $130^{\circ} \mathrm{C}$.

\section{Additional Information}

The applied method helps in understanding that the melting temperature does not necessarily include the processing temperature, as was found on the extrusion machine because the flow of the molten polymer also depends on its viscosity. The overall thermal behaviour of the grades used in this method allows the conclusion that the processing window is quite wide. Therefore, the used polymer (AAC) can be safely extruded from $130^{\circ} \mathrm{C}$. The overall thermal behaviour of the polymer used in this method suggests that the processing temperature range is slightly wide $\left(20-25^{\circ} \mathrm{C}\right)$; the technical aspects could apply to other polymers which will have different processing temperature ranges [16-18].

The decrease in viscosity improves the material flow and leads to more uniform extrudate (or filaments). Hence, additional information about the processing window can be obtained. After the viscoelastic and morphological characteristics had been identified, the rheological data were used to determine the enhanced processing temperature for melt spinning.

Using the Texas Instrument or applying Microsoft Office Excel Software by using (1) to (7) generated in this study is fast and accurate technique to calculate without the need for further statistical background.

\section{Conflict of Interests}

The author declares that there is no conflict of interests regarding the publication of this paper.

\section{Acknowledgments}

The author would like to thank Damascus University (Syria) and Dr. Alex Fotheringham from Heriot-Watt University (UK) for the support.

\section{References}

[1] H. F. Giles, J. R. Wagner, and E. M. Mount, Extrusion: The Definition Processing Guide and Hand Book, William Andrew Inc, Norwich, UK, 2005.

[2] National Industrial Chemicals Notification and Assessment Scheme (NICNAS), CAS Number 60961-73-1, National Industrial Chemicals Notification and Assessment Scheme (NICNAS), Canberra, Australia, 2003.

[3] I. M. Campbell, Introduction to Synthetic Polymers, Oxford University Press, Oxford, UK, 1994.

[4] Product User Manual, vol. 5 of Series Advanced Melt Flow Systems, Ray-Ran Test Equipment Ltd, Nuneaton, UK, 1998.

[5] D. Walton and P. Lorimer, Polymers, Oxford University Press, New York, NY, USA, 2000.

[6] C. D. Han, Rheology in Polymer Processing, Academic Press, New York, NY, USA, 1976.

[7] ANTEC, "ANTEC 1999 conference processing," Processing, vol. 1, pp. 1242-1243, 1999.

[8] C. Rawendaal, Polymer Extrusion, HANSER, Munich, Germany, 2001.

[9] J. A. Brydson, Flow Properties of Polymer Melts, George Godwin Limited, London, UK, 2nd edition, 1981.

[10] W. Michaeli, Extrusion Dies for Plastics and Rubber: Design and Engineering, Hanser, Munich, Germany, 1990.

[11] M. H. R. Ghoreishy, M. Razavi-Nouri, and G. Naderi, "Finite element analysis of flow of thermoplastic elastomer melt 
through axisymmetric die with slip boundary condition," Plastics, Rubber and Composites Processing and Applications, vol. 29, no. 5, pp. 224-228, 2000.

[12] H. A. Barnes, J. F. Hutton, and K. Walters, An Introduction to Rheology, Elsevier Science, Amsterdam, The Netherlands, 1989.

[13] A. C. T. Aarts, Analysis of the flow instabilities in the extrusion of polymeric melts [Ph.D. thesis], Eindhoven University of Technology, Eindhoven, The Netherlands, 1997.

[14] S. J. Kadolph and A. L. Langford, Textiles, Pearson Education, Upper Saddle River, NJ, USA, 2002.

[15] H. Brody, Synthetic Fibre Materials, Longman Group, London, UK, 1994.

[16] B. Younes and A. Fotheringham, "Factorial optimization of the effects of extrusion temperature profile and polymer grade on as-spun aliphatic-aromatic copolyester fibers. II. Crystallographic order," Journal of Applied Polymer Science, vol. 119, no. 4, pp. 1896-1904, 2011.

[17] B. Younes, A. Fotheringham, and H. M. EL-Dessouky, "Factorial optimization of the effects of extrusion temperature profile and polymer grade on as-spun aliphatic-aromatic copolyester fibers. I. Birefringence and overall orientation," Journal of Applied Polymer Science, vol. 118, no. 3, pp. 1270-1277, 2010.

[18] B. Younes and A. Fotheringham, "Factorial optimisation of the effects of extrusion temperature profile and polymer grade on as-spun aliphatic-aromatic co-polyester fibres III: mechanical properties," The Journal of the Textile Institute, vol. 103, no. 2, pp. 139-153, 2012. 

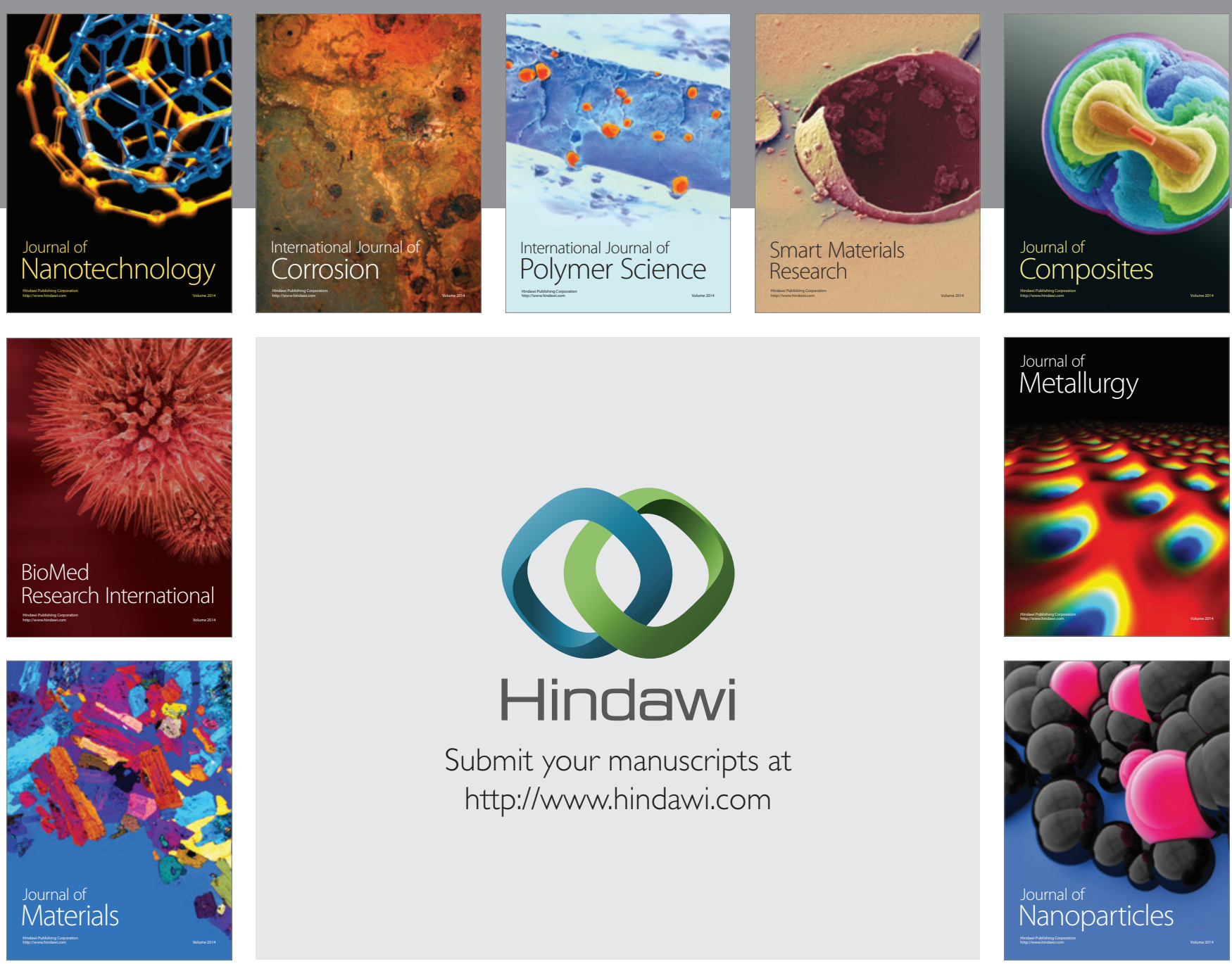

Submit your manuscripts at http://www.hindawi.com
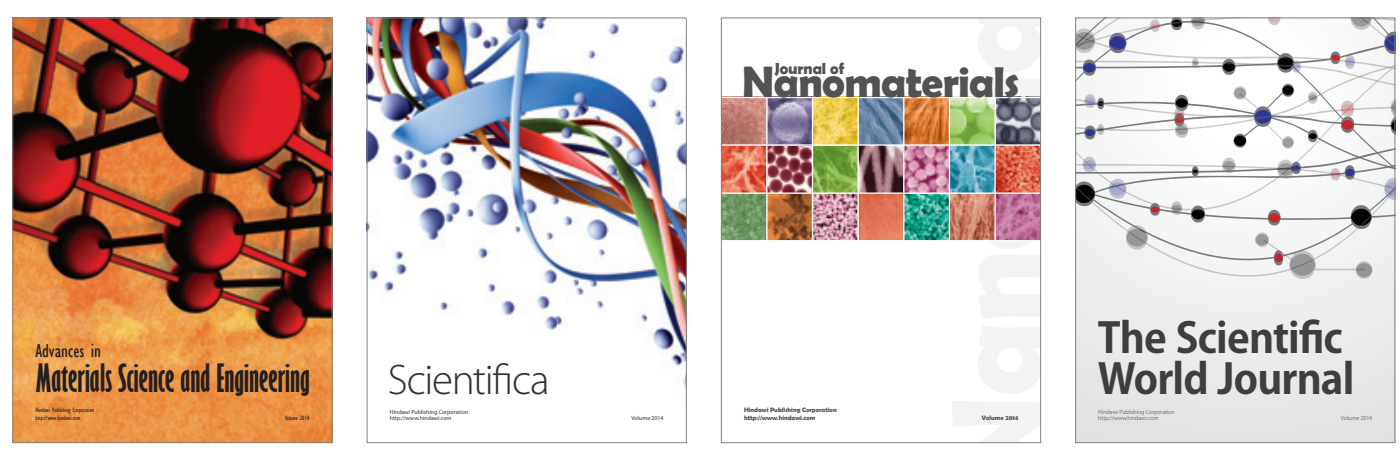

\section{The Scientific World Journal}
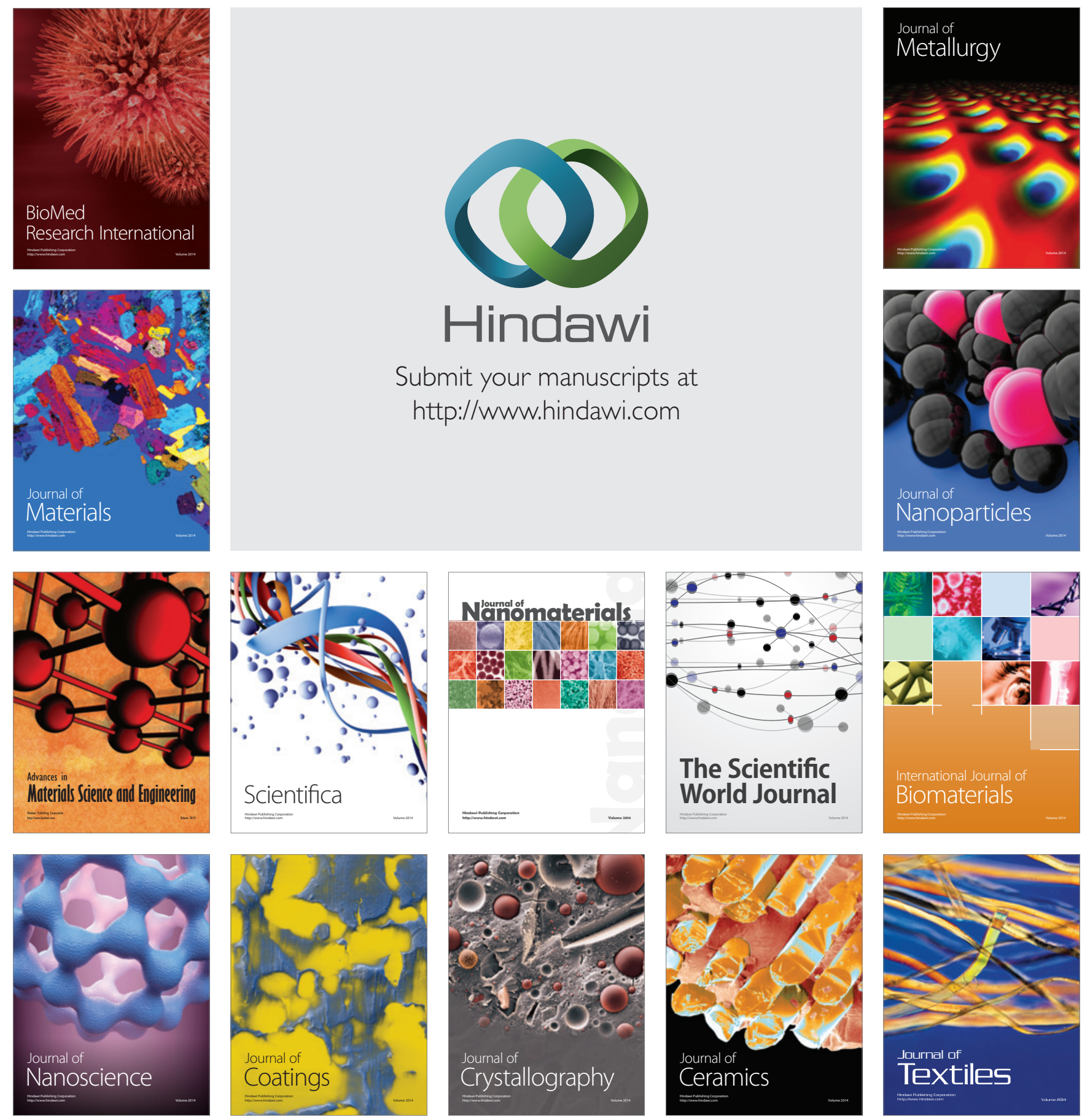